\title{
CITICOLINE EFFICIENCY ON COGNITIVE FUNCTION: A SYSTEMATIC REVIEW
}

\author{
N. Cano-Cuenca ${ }^{1,2}$, J. Solís-García del Pozo ${ }^{1,3}$, J. Jordán ${ }^{1,4}$
}

\begin{abstract}
Background: Citicoline is considered an ingredient in particular foods in the USA and is available in pharmaceutical form in Europe and Japan. It has been postulated to render positive effects on the nervous system, either by increasing levels of neurotransmitters, or by affording neuroprotection. Methods: Several clinical trials have shown the efficacy and safety of this biomolecule in several neurodegenerative diseases and in acute ischemic stroke. Here, we have performed a systematic review to validate the effect of citicoline on MMSE, memory, attention, and basic activity of daily living. In electronic database searches, we found 14 randomized clinical trials reporting citicoline effects on cognitive function. Findings: A positive effect of citicoline on MMSE in acute ischemic stroke was found, which was not evidenced for Alzheimer disease or vascular dementia. On activities of daily living, citicoline failed to exert beneficial effects in patients with acute ischemic stroke or progressive cognitive impairment. Conclusions: Given the present data there is no evidence that supports advising patients with cognitive alterations to take chronic citicoline supplements.
\end{abstract}

Key words: CDP-choline, cytidine, Alzheimer disease, dementia, cognition, meta-analysis, acute ischemic stroke.

\section{Introduction}

Besides being the central symptom of dementia, cognitive impairment is the principal cause of a wide range of disabilities affecting attention, mnesic, linguistic and visuo-spatial abilities (1). Alterations in cognitive functions are present in neurodegenerative diseases, including cerebrovascular disorders such a stroke or vascular dementia (2). Among the pharmacological arsenal tested in stroke is the biomolecule Citicoline (CDP-choline or cytidine-5'-diphosphocholine) (3). Although its mode of action is far from being clarified, evidence supports citicoline roles in cellular pathways related with neural cell death prevention. Thus, citicoline increases levels of neurotransmitters, including noradrenaline, dopamine and serotonin (4). Furthermore, citicoline might enhance tolerance to ischemic brain damage by preventing cell membrane damage and impaired phospholipid metabolism described during stroke (5). Preclinical evidence supports citicoline providing efficacy and optimal neuroprotective profile in

1. Departamento de Ciencias Médicas. Facultad de Medicina de Albacete. Universidad de Castilla-La Mancha (UCLM). Spain; 2. Servicio de Farmacia. Hospital de Hellín. Spain; 3. Servicio de Medicina Interna. Hospital General de Villarrobledo. Spain; 4. Grupo de Neurofarmacología. Instituto de Investigación en Discapacidades Neurológicas-UCLM. Spain.

Corresponding Author: Joaquín Jordán, Grupo Neurofarmacología. Departamento de Ciencias Médicas. Facultad de Medicina de Albacete. Universidad de CastillaLa Mancha. Calle Almansa, 14. Albacete-02008. Spain. Telephone. +34-967599200. Fax+34-967599327. e-mail: joaquin.jordan@uclm.es stroke animal models $(6,7)$.

This neuroprotective role leaded the clinician to perform clinical trials aimed to ascertain the efficacy of citicoline on stroke [8-13] and other neurodegenerative diseases $(8,14,15)$. However, the effect of citicoline on stroke is elusive (for literary reviews see (16-19), even more if take into account data from the latest clinical trials that failed to show beneficial results $(20,21)$. These neuroprotective effects lead other authors to suggest that citicoline might have beneficial impact on several cognitive domains (22), and several trials including patients of Alzheimer disease (10) or vascular dementia (23).

Meta-analysis combines findings from independent studies to assess the clinical effectiveness of healthcare interventions (22). Using this technique, the efficacy and safety of a drug $(24,25)$, or its lack of efficacy, such as in the case of the promising drug dimebon (26), can be determined.

The lack of a systematic review that put together all the information on citicoline effects on cognitive function was the starting point of this work. Thus in this study, we performed a systematic review of the literature on citicoline and its efficacy on impairment associated to neurodegenerative diseases such as alterations in minimental state examination, memory, attention and finally the plausible effects on basic activities of daily living. 


\section{Material and Methods}

We conducted a search for all clinical trials using citicoline to improve cognitive function, in patients affected by different pathologies causing neurological disorders. The studies were found by means of a MEDLINE and and in the Cochrane Central Register of Controlled Trials (CENTRAL) searches using the keywords "Citicoline" AND “cognitive» (July 2014). The bibliographic references of the selected articles were also examined to locate other possible publications not found in the above-mentioned search. The trials that were included meet the following criteria. 1. Doubleblind placebo controlled with random assignment to citicoline or placebo. 2. Inclusion of patient with altered cognitive function. 3. Specification of medication doses and formulation. 4. Written in English. We have found 99 studies. Of these, 73 were rejected for different reasons (figure 1). Of the 26 remaining studies, 14 were included in our systematic review (Table I and Figure 1). The quality of each study was determined by using Jadad score that considers aspect related to biases such as randomization, blinding and reporting of loss to followup (27). This instrument gives a score from 0 (the worst score) to 5 (the best score). Two investigators (NC-C, JJ), independently extracted those publications identified here that describe controlled studies of citicoline in cognitive impairment. Disagreements were resolved in discussion with a third investigator (JSGdP).

We collected data on patients' diagnosis, dosage used, duration of treatment and follow-up, inclusion and exclusion criteria and scales used for efficacy. Results were described for four domains: mini-mental state examination, memory, attention and basic activities of daily living.

- Mini-mental state examination (MMSE) (28). The MMSE is a common, validated screening instrument that is used as a general measure of cognitive function (lower score indicate greater impairment), includes questions about basic temporal and spatial orientation, attention, language, calculation, memory fixing and constructive praxis.

- Memory: Different scales were used to assess memory. Briefly, Randt memory test for longitudinal assessment of mild and/or moderate memory deficits (29), memory subscale of Alzheimer's Disease Assessment Scale (ADAS) (30) used to evaluate the severity of cognitive and noncognitive behavioral dysfunctions characteristic of persons with Alzheimer's disease, California Verbal Learning Test popular clinical and research test that claims to measure key constructs in cognitive psychology such as repetition learning, serial position effects, semantic organization, intrusions, and proactive interference (31), Logical Memory consisting in immediate repetition of short stories presented auditory (it is a subtest of Wechsler Memory Scale, a widely used clinical scale composing a number of subtest) (32) and the Rey Auditory Verbal Learning Test (RALVT) an easy to administer test that assesses many memory domains and is, therefore, widely used in the area of clinical neuropsychology (33).

- Attention: Two tests were used for determining the subject's attention. The Toulouse-Pieron Test and the Trail Making Test are accessible neuropsychological instruments that provides the examiner with information on a wide range of cognitive skills (11).

- Basic activities of daily living (disability): two scales were used, basically for the evaluation of self-care and mobility. Barthel Index, a scoring technique that measures the patient's performance in 10 activities of daily life (34) and the Index of Activities of Daily Living (ADL) a method of classifying heterogeneous groups of people with chronic illnesses, disabilities and impairments, and of describing their health needs and outcomes (35).

The statistical analyses were performed comparing citicoline with placebo in terms of efficacy wherever such comparison was possible. The efficacy measures were expressed as odds ratio or standardized mean diference with the relevant confidence interval (IC95\%). We have used a random effect where heterogeneity among studies was found. A funnel plot, if possible, were used to evaluate potential selection bias in the studies. Chi2 of heterogeneity and I2 inconsistency statistic were used to measure heterogeneity regarding study results. In all tests, the level of statistical significance used was $\mathrm{p}<0.05$. Analyses were performed using RevMan version 5.

\section{Results}

Our literature search revealed 14 clinical trials that were included in our study tested the efficacy of citicoline for improving cognitive functions in patients that were affected by altered cognition pathologies, such as vascular dementia, acute stroke, and Alzheimer disease.

\section{Effects of citicoline on MMSE}

Although we found four trials including 474 patients, of which 300 were treated with citicoline using the MMSE measure to evaluate cognitive function.

In two clinical trials, citicoline efficacy was tested in patients with vascular dementia, giving contradictory results. Chandra et al reported a marked improvement on the MMSE score compared with patients taking after two months (MMSE score: 23 in citicoline group and 14.4 in placebo group) and after 10 months (MMSE score: 23 in citicoline group and 12.2 placebo group) (12). On the other hand, Cohen et al. found no significant changes in MMSE scores at 6 and 12 months (23).

In patients with acute ischemic stroke, Clark et al., evaluated the effect of three daily doses of citicoline (500, 1000 and $2000 \mathrm{mg}$ ) versus placebo (36). At 12 weeks, citicoline increased the percentage of patients with 
Table 1

Clinical trials included in this review

\begin{tabular}{|c|c|c|c|c|c|c|c|}
\hline Author (year) [Ref] & $\begin{array}{l}\text { Jadad } \\
\text { score }\end{array}$ & Disease & Patients & Dose Daily & Via & $\begin{array}{l}\text { Duration } \\
\text { (days) }\end{array}$ & Efficacy measures \\
\hline Chandra B (1992) (12) & 4 & Vascular dementia & 146 & $750 \mathrm{mg}$ & IV & 60 & $\begin{array}{l}\text { Ischemia Scale of Hachinski } \\
\text { Mini-mental state examination }\end{array}$ \\
\hline Piccoli F (1994) (37) & 2 & Chronic cerebrovascular disease & 92 & $1000 \mathrm{mg}$ & $\mathrm{IM}$ & 63 & $\begin{array}{l}\text { Randt Memory Test } \\
\text { Scale of emotional and behavioral } \\
\text { control } \\
\text { Toulouse-Pieron Test }\end{array}$ \\
\hline Spiers PA (1996) (9) & 5 & Aging & 94 & $\begin{array}{l}1000 \mathrm{mg} \\
2000 \mathrm{mg}\end{array}$ & OV & $\begin{array}{l}90 \\
60\end{array}$ & Verbal memory \\
\hline Capurso A (1996) (13) & 3 & Chronic cerebrovascular disease & 31 & $1000 \mathrm{mg}$ & $\mathrm{IM}$ & 63 & $\begin{array}{l}\text { Brane and Steen Scale } \\
\text { Rating Scale } \\
\text { Test Deux Barrages } \\
\text { Randt Memory Test }\end{array}$ \\
\hline Clark WM (1997) (36) & 3 & Acute ischemic stroke & 259 & $\begin{array}{l}500 \mathrm{mg} \\
1000 \mathrm{mg} \\
2000 \mathrm{mg}\end{array}$ & $\mathrm{OV}$ & 42 & $\begin{array}{l}\text { Barthel Index } \\
\text { Modified Rankin scale } \\
\text { Mini-mental state examination }\end{array}$ \\
\hline Alvarez XA (1999) [10] & 3 & Alzheimer disease & 30 & $1000 \mathrm{mg}$ & $\mathrm{OV}$ & 84 & $\begin{array}{l}\text { Mini-mental state examination } \\
\text { Alzheimer's disease assessment scale } \\
\text { Alzheimer's disease assessment scale- } \\
\text { cognitive subscale }\end{array}$ \\
\hline Clark WM (1999) [41] & 5 & Acute ischemic stroke & 394 & $500 \mathrm{mg}$ & $\mathrm{OV}$ & 84 & $\begin{array}{l}\text { Barthel Index } \\
\text { Rankin scale }\end{array}$ \\
\hline Clark WM (2001) [42] & 5 & Acute ischemic stroke & 899 & $2000 \mathrm{mg}$ & $\mathrm{OV}$ & 84 & $\begin{array}{l}\text { Barthel Index } \\
\text { Clinician's Global Impressions scale }\end{array}$ \\
\hline Cohen RA (2003) [23] & 3 & Vascular dementia & 39 & $1000 \mathrm{mg}$ & $\mathrm{OV}$ & 365 & $\begin{array}{l}\text { Mini-mental state examination Execu- } \\
\text { tive/Attention } \\
\text { Memory } \\
\text { Visuospatial } \\
\text { Language } \\
\text { Phychomotor }\end{array}$ \\
\hline Brown ES (2007) [15] & 4 & Bipolar disorder & 44 & $500-2000 \mathrm{mg}$ & $\mathrm{OV}$ & 84 & $\begin{array}{l}\text { Inventory of Depressive Symptomato- } \\
\text { logy-Self-report } \\
\text { Young Mania Rating Scale } \\
\text { Rey Auditory Verbal Learning Test }\end{array}$ \\
\hline Dávalos A (2012) [20] & 4 & Acute ischemic stroke & 2298 & $2000 \mathrm{mg}$ & $\mathrm{OV} / \mathrm{IV}$ & 90 & $\begin{array}{l}\text { Barthel Index } \\
\text { Modified Rankin Score }\end{array}$ \\
\hline Putignano S (2012) [43] & 1 & Geriatric syndrome & 197 & $500-2000 \mathrm{mg}$ & IV / IM & 180 & $\begin{array}{l}\text { NIHSS } \\
\text { Rankin Scale } \\
\text { Activities of Daily Living IADL }\end{array}$ \\
\hline Zafonte RD (2012) [38] & 5 & Brain injury & 1213 & $2000 \mathrm{mg}$ & $\mathrm{OV}$ & 90 & $\begin{array}{l}\text { Traumatic Brain Injury } \\
\text { Clinical Trials Network Core Batery }\end{array}$ \\
\hline Alvarez-Sabin J (2013) [39] & 2 & Vascular dementia & 347 & $1000 \mathrm{mg}$ & $\mathrm{OV}$ & 365 & $\begin{array}{l}\text { Attention } \\
\text { Temporal orientation } \\
\text { Language } \\
\text { Memory } \\
\text { Spatial Perception } \\
\text { Motor speed }\end{array}$ \\
\hline
\end{tabular}

an optimal outcome in the MMSE ( 225$)$. Remarkably, this effect appeared not dose dependent, since it was observed at 500 and $2000 \mathrm{mg}$ but not $1000 \mathrm{mg}$ (36).

In Alzheimer disease patients, Alvarez et al. did not detect a difference in the MMSE score between placebo and citicoline (1000 mg, 12 weeks) (10).

\section{Citicoline effects on memory}

In table II, we have summarized the eight clinical trials, including 1890 patients, which evaluated citicoline effects on memory function $(9,10,13,15,23,37,38)$.

Two trials used the Randt Memory Test to ascertain citicoline efficacy in patients with chronic cerebrovascular disease. First, Piccoli et al. revealed that citicoline induced a constant and progressive improvement $(p<0.05)(37)$. 
Table 2

Clinical trials evaluating citicoline effects on memory

\begin{tabular}{|c|c|c|c|}
\hline Author (REF) & Disease & Scale & $\mathrm{p}$ \\
\hline Spiers (11) & Aging & Logical Memory* & N.S. \\
\hline Capurso (10) & Cerebrovascular Disease & Rand Memory Test & $\mathrm{p}<0.05$ \\
\hline Alvarez (12) & Alzheimer's disease & Alzheimer’s disease assessment scale-Memory & N.S. \\
\hline \multirow[t]{3}{*}{ Brown (15) } & Bipolar Disorder & RAVLT total words & N.S. \\
\hline & & RAVLT delayed recall & N.S. \\
\hline & & RAVLT alternative Word list & $\mathrm{p}<0.05$ \\
\hline Zafonte (39) & Traumatic Brain Injury & California Verbal Learning Test & N.S. \\
\hline
\end{tabular}

N.S. Non-significant. RAVLT, Rey Auditory Verbal Learning Test.

Second, in a subtest of this test, Capurso el al. found a significant difference in the memory index $(p<0.05)(13)$. However, in patients with vascular dementia, citicoline failed to improve the California Verbal Learning Test $(\mathrm{p}=0.36)$ and Logical Memory $(\mathrm{p}=0.5)$ (23). Lack of citicoline-induced positive effects were also reported by Alvarez-Sabin et al. Using the Auditory Verbal Learning Test, these authors did not detect differences in patients with post-stroke vascular cognitive impairment at 6 and 12 weeks ( $\mathrm{p}=0.807$ y $\mathrm{p}=0.873$ ) (39).

In the citicoline brain injury treatment trial(COBRIT), citicoline failed to afford any improvement in the California Verbal learning Test score in patients with traumatic brain injury (38). In patients with bipolar disorder with cocaine dependence, Brown et al. reported that citicoline leads to an enhancement in the RAVLT alternative Word list $(\mathrm{p}=0.006)$ but not in RAVLT total Word ( $\mathrm{p}=0.439)$ or RAVLT delayed recall $(\mathrm{p}=0.105)(15)$. In addition, two more trials described a positive but not statistically significant tendency to improve memory in volunteering patients with relatively inefficient memory (9) or Alzheimer disease (10).

\section{Effects of citicoline on attention}

We identified five trials analyzing citicoline effects on attention, enclosing a total of 1.721 patients $(23,37-40)$. In patients with chronic cerebrovascular disease, citicoline induced a significant decrease in the number of incorrect responses in the Toulouse-Pieron test $(\mathrm{p}<0.05)(37)$. Similarly, Alvarez-Sabin, at $6(\mathrm{p}=0.019)$ and $12(\mathrm{p}=0.014)$ months of treatment, evidenced less deterioration of post-stroke vascular cognitive impairment in attentionexecution (Stroop Color Word Interference test, Trails A and B and Symbol digits Modalities Test, Mental control, Digit Span) (39).
However, using the Trail Making Test scores, we did not find citicoline-induced improvements in patients affected by Alzheimer disease $(p=0.74)(40)$, vascular dementia $(\mathrm{p}=0.58)(23)$ or traumatic brain injury (38).

\section{Figure 1}

Flow chart outlining the search strategy and results of the different steps

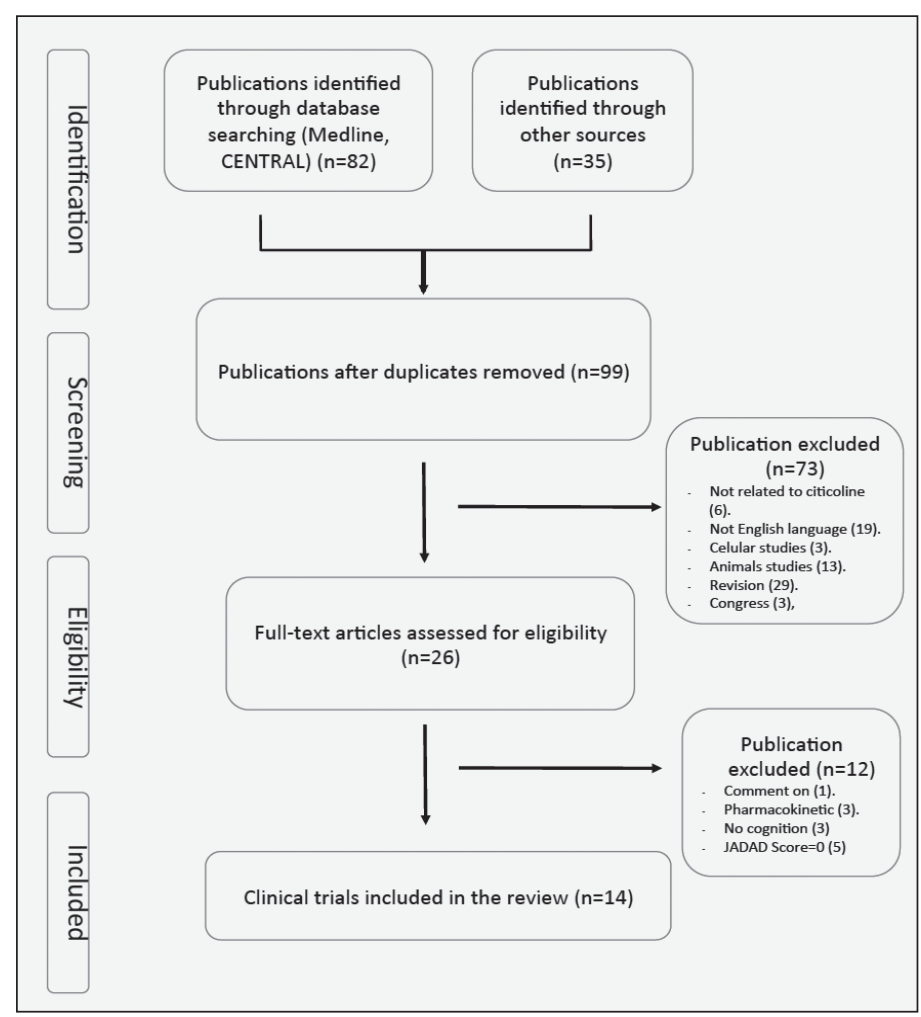




\section{Figure 2}

Forest plots showing individual and pooled odd ratio (95\%) for the associations between citicoline (2000 $\mathrm{mg}$ and $500 \mathrm{mg})$ and Barthel index ( $\geq 95)$

\begin{tabular}{|c|c|c|c|c|c|c|c|}
\hline Study or Subgroup & \multicolumn{2}{|c|}{ Citicoline $500 \mathrm{mg}$} & \multicolumn{2}{|c|}{$\begin{array}{l}\text { Placeho } \\
\text { Events Total }\end{array}$} & Weight & $\begin{array}{l}\text { Odds Ratio } \\
\text { M-H, Random, } 95 \% \mathrm{Cl}\end{array}$ & $\begin{array}{l}\text { Odds Ratio } \\
\text { M-H, Random, } 95^{\underline{p_{h}} \mathrm{Cl}}\end{array}$ \\
\hline Clark 1997 & 33 & 62 & 21 & 63 & $43.6 \%$ & $2.28[1.10,4.69]$ & \\
\hline Clark 1999 & 107 & 267 & 51 & 127 & $56.4 \%$ & $1.00[0.65,1.53]$ & \\
\hline Total $(95 \%$ Cl) & & 329 & & 190 & 100.0\% & $1.43[0.64,3.19]$ & \\
\hline \multirow{2}{*}{\multicolumn{7}{|c|}{$\begin{array}{l}\text { Total events } \quad 140 \quad 72 \\
\text { Heterogeneity: Tau }=0.25 ; \mathrm{Ch}^{2}=3.69, \mathrm{df}=1(P=0.05) ; \mathbb{F}^{2}=73 \% \\
\text { Test for overall effect: } Z=0.87(P=0.38)\end{array}$}} & \\
\hline & & & & & & & \begin{tabular}{ll|lll} 
& 1 & 1 & 1 & 1 \\
0.01 & 0.1 & 1 & 100 \\
Favours placebo & Favours citicoline
\end{tabular} \\
\hline & \multicolumn{2}{|c|}{ Citicoline $2000 \mathrm{mg}$} & \multicolumn{2}{|c|}{ Placebo } & & Odds Ratio & \multirow{2}{*}{$\begin{array}{l}\text { Odds Ratio } \\
\text { M-H, Random, } 95 \% \mathrm{Cl}\end{array}$} \\
\hline Study or Subgroup & Events & Total & Events & Total & Weight & $\mathrm{t}$ M-H, Random, $95 \%$ Cl $\mathrm{Cl}$ & \\
\hline Clark 1997 & 30 & 66 & 21 & 65 & $12.3 \%$ & $1.75[0.86,3.55]$ & $\dot{E}$ \\
\hline Clark 2001 & 181 & 453 & 156 & 446 & $39.0 \%$ & $1.24[0.94,1.62]$ & \multirow{2}{*}{ 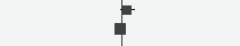 } \\
\hline Davalos 2012 & 307 & 1148 & 321 & 1150 & $48.7 \%$ & $0.94[0.78,1.13]$ & \\
\hline Total $(95 \% \mathrm{Cl})$ & & 1667 & & 1661 & $100.0 \%$ & $1.13[0.86,1.49]$ & 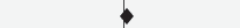 \\
\hline \multirow{2}{*}{\multicolumn{7}{|c|}{$\begin{array}{l}\text { Heterogeneity: } \text { Tau }^{2}=0.03 ; \mathrm{Ch}^{2}=4.70, \text { df }=2(P=0.10) ; I^{2}=57 \% \\
\text { Test for overall effect. } Z=0.86(P=0.39)\end{array}$}} & \\
\hline & & & & & & & \begin{tabular}{cc|cc} 
& 1 & 1 & 1 \\
0.01 & 0.1 & 1 & 100 \\
Favours placebo & Favours citicoline
\end{tabular} \\
\hline
\end{tabular}

\section{Effects of citicoline on basic activities of daily living}

The effect of citicoline on the patient ability to perform activities of daily living was evaluated in 5 clinical trials that included 4137 patients, 2334 of which were treated with citicoline.

In acute ischemic stroke patients, Clark et al. evaluated citicoline efficacy in three clinical trials, leading to heterogeneous results. Interestingly, in the first trial, with citicoline administered at 500, 1000, and $2000 \mathrm{mg}$, only at a daily dose of $500 \mathrm{mg}$ citicoline resulted in a Barthel-index improvement ( $p=0.03)$ (36). Their second trial was addressed to compare citicoline $(500 \mathrm{mg}$ ) versus placebo (41), but this did not yield positive results. In the third trial, the authors compared a daily dose of $2000 \mathrm{mg}$ citicoline versus placebo. Although initially (at 6 weeks) a higher proportion of patients in the citicoline group showed a score higher or equal to 95(placebo $21 \%$, citicoline $27 \%$; $\mathrm{p}=0.04$ ), this difference was lost at 12 weeks (42). In addition, in a different trial, Davalos et al. did not find citicoline effects in this kind of patients (20). Our meta-analysis of these data shows that citicoline did not significantly alter the Barthel index at the doses of either 500mg (OR 1.43; IC 95\% 0.64-3.19)or 2000mg(OR 1.13; IC 95\% 0.86-1.49) (Figure 2).

Using the ADL scale in elderly patients with progressive cognitive impairment, Putignano et al., did not find effectiveness for citicoline, although, they denoted a trend towards favorable scores in the functional independence (43)

\section{Discussion}

Prompted by the fact that citicoline has been shown to be a useful treatment for neurodegenerative and cerebrovascular diseases, we have evaluated its ability to improve cognitive function by performing a systematic review. To do so, we focused on scales that measure aspects such as MMSE, memory, attention, and basic activity of daily living.

Our data reveal a positive effect of citicoline on MMSE in acute ischemic stroke, which was not evidenced for other diseases where cognitive function is compromised, including Alzheimer disease or vascular dementia. However, this positive improvement was found in a single study, and only at a daily dose of 500 and $2000 \mathrm{mg}$ but not $1000 \mathrm{mg}$. So, it will be interesting to corroborate these data in a new clinical trial. In addition, in vascular dementia, our study revealed contradictory results, which makes it difficult to draw solid conclusions. Furthermore, we found lack of evidence for citicoline effects on cognitive impairment associated to Alzheimer disease. This conclusion seems contradictory to the previous conclusion reached by Secades in a nice and elegant, but not systematic, review (17).

In addition, eight studies reporting citicoline effects on memory were found. In chronic cerebrovascular disease patients, two studies yielded favorable results. However, other studies failed to show a positive effect on post-stroke vascular cognitive impairment, $\mathrm{AD}$, or aging. Unfortunately, we were unable to perform a metaanalysis as the authors used different scales with different scores and thresholds to measure sensibility. These disparities constitute a handicap to find plausible positive effects.

We have also analyzed the effects of citicoline on attention. Positive results were observed in two studies performed with post-stroke patients and chronic cerebrovascular disease. However, citicoline failed to produce this positive result when the patient suffered from Alzheimer disease, traumatic brain injury, or vascular dementia.

Our last goal was focused on the effects of citicoline on the activities of daily living. Our meta-analysis, which included four trials, revealed that citicoline failed to exert beneficial effects in patients with acute ischemic stroke (Barthel index) or progressive cognitive impairment (ADL score).

Why citicoline improves some cognitive impairments but fails to do so with others remains unknown (43, 44, 45) Pre-clinical evidence supports citicoline efficacy and an optimal neuroprotective profile in stroke animal models (7). In a recent review, Overgaard concluded that citicoline is the only drug that, in different clinical stroke trials, continuously showed neuroprotective effects (3).

However, we cannot ignore that often important causes of irreproducibility of experimental results in clinical settings are the use of large drug doses in most animal experiments (18) or the lack of methodological rigor, and these lead to an inflated treatment effect (46) Considering that citicoline is an essential intermediate in the synthesis of structural phospholipids of cell membranes and its formation from phosphorylcholine is the rate-limiting step of this biosynthetic pathway, one could hypothesize that it needs to have a strict control. In fact, citicoline is hydrolysed into choline and 
cytidine to be resynthesized later in the brain (47). In this scenario, long treatment periods would result in a negative feedback and result in readjustment of the available citicoline levels, yielding a non-efficient drug. Supporting this idea, Baab et al. found that phospholipid synthesis and turnover were stimulated at 6 but not 12 weeks of oral citicoline treatment. Moreover, these authors correlated results from the California Verbal learning test with an increase in phophodiesters (48). Then, only under acute damage (e.g. acute stroke), where this homeostatic response does not efficiently regulate endogenous values, citicoline administration results in an efficient protection. On the other hand, in acute events citicoline might result in an inhibition of cell death pathways. For instance, in an experimental model, citicoline markedly lowered brain edema and bloodbrain barrier permeability, enhanced the activities of superoxide dismutase, increased glutathione levels, and reduced the levels of malondialdehyde and lactic acid (49). Other mechanisms suggested to be involved include prevention of phospholipase A2 activation (50), which is involved in transient cerebral ischemia (51).

There is a Cochrane's Systematic review about this topic performed by Fioravanti $\mathrm{M}$ and Yanagi $\mathrm{M}$, that yielded different results (52). The authors concluded that there was some evidence that CDP-choline has a positive effect on memory and behaviour. The effect on attention measures was not significant $(\mathrm{p}=0.22)$. Nonetheless, the characteristics of this review are different from ours since the outcome analyzed differ. For instance, the effect of citicoline on the MMSE and on activities of daily living is novel in our review. We have to acknowledge that our study presents limitations related to the difficult process of selecting trials using citicoline. In addition, our systematic review shows the heterogeneity of trials using citicoline. This heterogeneity is present in parameters such as treatment duration, the number of patients, the follow-up period, and the scores used. Moreover, we were negatively surprised by the way the authors of the trials had reported their results. Whereas some authors gave mean scores, others categorized them when they referred to the same scale. Indeed, we found that 5 reached a Jadad score of zero $(8,14,21,53,54)$, which is indicative of a lack of answer to relevant key questions such as «Was the study described as randomized, or as double blind?», «Was there a description of withdrawals and dropouts?»Due to these discrepancies, it is difficult to make a thorough analysis of the data and might easily lead to wrong interpretations.

Finally, although our study was not undertaken to determine citicoline safety, we validate the general idea that citicoline presents a good safety profile. Ten of the trials included in our study described adverse events. Enclosing 2254 patients in total, 1400 were treated with citicoline. The side effects most frequently reported were effects on the central nervous system in both the citicoline (127 events, 10\%) and the placebo (103 events, 13\%) groups. However, we did not find significant differences between these groups.

In summary, our data suggests that citicoline may improve MMSE in acute stroke patients. However, to reach a solid conclusion for this and other chronic diseases such as Alzheimer disease and vascular dementia, we need to reach an agreement on the test scales and how to report the scores before performing more trials. Awaiting the completion of new clinical trials including higher numbers of patients in order to obtain more consistent results, we would not advise the use of citicoline as effective treatment in patients with cognitive impairment.

Ethical Standards: None disclosed.

Conflicts of Interest: The authors declare that they have not conflicts of interest.

\section{References}

1. Ritchie K, Portet F. 'I think therefore I am': improving cognition. Curr Opin Psychiatry 2006;19:570-574.

2. Roh JH, Lee JH. Recent updates on subcortical ischemic vascular dementia. J Stroke 2014;16:18-26.

3. Overgaard K. The effects of citicoline on acute ischemic stroke: a review. JStroke Cerebrovasc Dis2014;23:1764-1769.

4. Petkov VD, Stancheva SL, Tocuschieva L, Petkov VV. Changes in brain biogenic monoamines induced by the nootropic drugs adafenoxate and meclofenoxate and by citicholine (experiments on rats). Gen Pharmacol 1990;21:71-75.

5. Goto Y, Okamoto S, Yonekawa Y, et al. Degradation of phospholipid molecular species during experimental cerebral ischemia in rats. Stroke. 1988;19:728-735.

6. Davalos A, Secades J. Citicoline preclinical and clinical update 2009-2010. Stroke. 2011;42:S36-39.

7. Bustamante A, Giralt D, Garcia-Bonilla L, Campos M, Rosell A, Montaner J. Citicoline in pre-clinical animal models of stroke: a meta-analysis shows the optimal neuroprotective profile and the missing steps for jumping into a stroke clinical trial. J Neurochem 2012;123:217-225.

8. Calatayud Maldonado V, Calatayud Perez JB, Aso Escario J. Effects of CDPcholine on the recovery of patients with head injury. J Neurol Sci 1991;103 Suppl:S15-18.

9. Spiers PA, Myers D, Hochanadel GS, Lieberman HR, Wurtman RJ. Citicoline improves verbal memory in aging. Arch Neurol 1996;53:441-448.

10. Alvarez XA, Mouzo R, Pichel V, et al. Double-blind placebo-controlled study with citicoline in APOE genotyped Alzheimer's disease patients. Effects on cognitive performance, brain bioelectrical activity and cerebral perfusion. Methods Find Exp Clin Pharmacol 1999;21:633-644.

11. Bowie CR, Harvey PD. Administration and interpretation of the Trail Making Test. Nat Protoc 2006;1:2277-2281.

12. Chandra B. Treatment of multi-infarct dementia with citicholine. J Stroke Cerebrovasc Dis 1992;2:232-233.

13. Capurso A, Capurso S, Panza F, Solfrizzi V, Mastroianni F, Giaquinto EA. Efficacy of cytidine diphosphate choline in patients affected by chronic cerebrovascular disease. Clin Drug Invest 1996;12: 26-38.

14. Cacabelos R, Caamano J, Gomez MJ, Fernandez-Novoa L, Franco-Maside A, Alvarez XA. Therapeutic effects of CDP-choline in Alzheimer's disease. Cognition, brain mapping, cerebrovascular hemodynamics, and immune factors. Ann N Y Acad Sci 1996;777:399-403.

15. Brown ES, Gorman AR, Hynan LS. A randomized, placebo-controlled trial of citicoline add-on therapy in outpatients with bipolar disorder and cocaine dependence. J Clin Psychopharmacol 2007;27:498-502.

16. Overgaard K, Meden P. Citicoline--the first effective neuroprotectant to be combined with thrombolysis in acute ischemic stroke? J Neurol Sci 2006;247:119-120.

17. Secades JJ. Citicoline: pharmacological and clinical review, 2010 update. Rev Neurol 2011;52 Suppl 2:S1-S62.

18. Grieb P. Neuroprotective properties of citicoline: facts, doubts and unresolved issues. CNS drugs 2014;28:185-193.

19. Garcia-Cobos R, Frank-Garcia A, Gutierrez-Fernandez M, Diez-Tejedor E. Citicoline, use in cognitive decline: vascular and degenerative. J Neurol Sci 2010;299:188-192.

20. Davalos A, Alvarez-Sabin J, Castillo J, et al. Citicoline in the treatment of acute ischaemic stroke: an international, randomised, multicentre, placebo- 
controlled study (ICTUS trial). Lancet 2012;380:349-357.

21. Cotroneo AM, Castagna A, Putignano S, et al. Effectiveness and safety of citicoline in mild vascular cognitive impairment: the IDEALE study. Clin Interv Aging 2013;8:131-137.

22. Egger M, Smith GD, Altman D. Systematic reviews in health care: Metaanalysis in context. London. 2008.

23. Cohen RA, Browndyke JN, Moser DJ, Paul RH, Gordon N, Sweet L. Longterm citicoline (cytidine diphosphate choline) use in patients with vascular dementia: neuroimaging and neuropsychological outcomes. Cerebrovasc Dis 2003;16:199-204.

24. Minguez-Minguez S, Solis-Garcia Del Pozo J, Jordan J. Rasagiline in Parkinson's disease: A review based on meta-analysis of clinical data. Pharmacol Res 2013;74:78-86.

25. Solis-Garcia del Pozo J, Minguez-Minguez S, de Groot PW, Jordan J. Rasagiline meta-analysis: a spotlight on clinical safety and adverse events when treating Parkinson's disease. Expert Opin Drug Saf 2013;12:479-486.

26. Cano-Cuenca N, Solis-Garcia del Pozo JE, Jordan J. Evidence for the efficacy of latrepirdine (Dimebon) treatment for improvement of cognitive function: a meta-analysis. J Alzheimers Dis 2014;38:155-164.

27. Jadad AR, Moore RA, Carroll D, et al. Assessing the quality of reports of randomized clinical trials: is blinding necessary? Control Clin Trials 1996;17:1-12.

28. Folstein MF, Folstein SE, McHugh PR. «Mini-mental state». A practical method for grading the cognitive state of patients for the clinician. J Psychiatr Res 1975;12:189-198.

29. Fioravanti M, Thorel M, Ramelli L, Napoleoni A. Reliability between the five forms of the Randt Memory Test and their equivalence. Arch Gerontol Geriatr 1985;4:357-364.

30. Rosen WG, Mohs RC, Davis KL. A new rating scale for Alzheimer's disease. The American journal of psychiatry 1984;141:1356-1364.

31. Elwood RW. The California Verbal Learning Test: psychometric characteristics and clinical application. Neuropsychol Rev 1995;5:173-201.

32. Brooks DN. Wechsler Memory Scale performance and its relationship to brain damage after severe closed head injury. J Neurol Neurosurg Psychiatry 1976;39:593-601.

33. Marques NO, Caro IA, Uterga Valiente JM, Rodriguez SM. Normative data for a Spanish version of the Rey auditory-verbal learning test in older people. Span J Psychol 2013;16:E60.

34. Granger CV, Dewis LS, Peters NC, Sherwood CC, Barrett JE. Stroke rehabilitation: analysis of repeated Barthel index measures. Arch Phys Med Rehabil 1979;60:14-17.

35. Katz S, Akpom CA. 12. Index of ADL. Med Care 1976;14:116-118.

36. Clark WM, Warach SJ, Pettigrew LC, Gammans RE, Sabounjian LA. A randomized dose-response trial of citicoline in acute ischemic stroke patients. Citicoline Stroke Study Group. Neurology 1997;49:671-678.

37. Piccoli F, Battistini N, Carbonin P, et al. CDP-choline in the treatment of chronic cerebrovasculopathies. Arch Gerontol Geriatr 1994;18:161-168.

38. Zafonte RD, Bagiella E, Ansel BM, et al. Effect of citicoline on functional and cognitive status among patients with traumatic brain injury: Citicoline Brain Injury Treatment Trial (COBRIT). JAMA 2012;308:1993-2000.

39. Alvarez-Sabin J, Ortega G, Jacas C, et al. Long-term treatment with citicoline may improve poststroke vascular cognitive impairment. Cerebrovasc Dis 2013;35:146-154.

40. Alvarez XA, Pichel V, Perez P, et al. Double-blind, randomized, placebocontrolled pilot study with anapsos in senile dementia: effects on cognition, brain bioelectrical activity and cerebral hemodynamics. Methods Find Exp Clin Pharmacol 2000;22:585-594.

41. Clark WM, Williams BJ, Selzer KA, Zweifler RM, Sabounjian LA, Gammans RE. A randomized efficacy trial of citicoline in patients with acute ischemic stroke. Stroke; a journal of cerebral circulation 1999;30:2592-2597.

42. Clark WM, Wechsler LR, Sabounjian LA, Schwiderski UE. A phase III randomized efficacy trial of $2000 \mathrm{mg}$ citicoline in acute ischemic stroke patients. Neurology 2001;57:1595-1602.

43. Putignano S, Gareri P, Castagna A, et al. Retrospective and observational study to assess the efficacy of citicoline in elderly patients suffering from stupor related to complex geriatric syndrome. Clin Interv Aging 2012;7:113118.

44. Adibhatla RM. Citicoline in stroke and TBI clinical trials. Nat Rev Neurol 2013;9:173.

45. Saver JL. Citicoline: update on a promising and widely available agent for neuroprotection and neurorepair. Rev Neurol Dis 2008;5:167-177.

46. Sena ES, Currie GL, McCann SK, Macleod MR, Howells DW. Systematic reviews and meta-analysis of preclinical studies: why perform them and how to appraise them critically. J Cereb Blood Flow Metab 2014;34:737-742.

47. Ramos-Cabrer P, Agulla J, Argibay B, Perez-Mato M, Castillo J. Serial MRI study of the enhanced therapeutic effects of liposome-encapsulated citicoline in cerebral ischemia. Int J Pharm 2011;405:228-233.

48. Babb SM, Wald LL, Cohen BM, et al. Chronic citicoline increases phosphodiesters in the brains of healthy older subjects: an in vivo phosphorus magnetic resonance spectroscopy study. Psychopharmacology 2002;161:248-254.

49. Qian K, Gu Y, Zhao Y, Li Z, Sun M. Citicoline protects brain against closed head injury in rats through suppressing oxidative stress and calpain overactivation. Neurochem Res 2014;39:1206-1218.

50. Adibhatla RM, Hatcher JF. Citicoline decreases phospholipase A2 stimulation and hydroxyl radical generation in transient cerebral ischemia. J Neurosci Res 2003;73:308-315.

51. Adibhatla RM, Hatcher JF, Dempsey RJ. Phospholipase A2, hydroxyl radicals, and lipid peroxidation in transient cerebral ischemia. Antioxidants \& redox signaling 2003;5:647-654.

52. Fioravanti M, Yanagi M. Cytidinediphosphocholine (CDP-choline) for cognitive and behavioural disturbances associated with chronic cerebral disorders in the elderly. Cochrane Database Syst Rev. 2005;Apr 18 (2):CD000269.

53. Cacabelos R, Alvarez XA, Franco-Maside A, Fernandez-Novoa L, Caamano J. Effect of CDP-choline on cognition and immune function in Alzheimer's disease and multi-infarct dementia. Ann N Y Acad Sci 1993;695:321-323.

54. Cacabelos R, Alvarez A, Fenandez-Novoa L, Lombardi VR. A pharmacogenomic approach to Alzheimer's disease. Acta Neurol Scand Suppl 2000;176:12-19. 